\section{A CASE OF}

\section{CONGENITAL ATRESIA OF THE DUODENUM TREATED SUCCESSFULIY BY OPERATION.}

By N. P. ERNST,

CHIET SETigEON AT ST. ELIZABETH'S HOSPITAL, COPENHAGEN, DENMARK.

The following report may prove to be of some interest, because there is only one instance known to me in surgical literature of a case of congenital atresia of the small intestine in which a surgical operation was successful. In that case, however, recorcled by P. Fockens, of Rotterdan, the atresia lay a little above the ileo-caecal valve, so that the following will be the first instance ever reported of congenital atresia of the duodenum successfully treated by an operation.

Congenital Atresia of the Duodenum below Vater's Papilla: Duodeno-enterostomy : Recovery.

The patient was a boy, born on November 19th, 1914 labour was spontaneous. I was present at the birth, and for some time saw the infant almost daily. The parents were healthy, but although they had been married for three years this was their first child. The child was robust at birth, and there was no history of deformity in its family. It weighed 4,300 grams, and showed nö exterual sign of any mal. formation. From the first the child always vomited after suckling: On the third day it took the breast more actively than at first; but two or three hours later it began to vomit, with almost explosive violence: Very little urine was passed, and the motions were limited to a small amount of typical meconium, without a particle of digested mill. The child was treated both with castor on and enemata, and the oil, at all events at first, caused a larger quantity of meconium to come away. - Rectal exannination revealed no abnormal condition of the bowels. The child lost weight rapidly, to the amount of about 700 grams during the first week.

I diagnosed the case as high. seated intestinal stenosis or atresia and suggested to the parents that it would be bast to operate on the infant; but they wished flrst to consult a children's specialist, Professor Monrad. In all essentials he shared my view about the condition of the child; but its gemeral health br otherwise so remarkably good, he considered that we could not exclude the possibility that the stenosis night perhaps be remedied by suitable medical treat ment, such as that which he successfully used for congenital pyloric stenosis. He thought it therefore advisable to change the infant's diet, and wash ou the stomach daily; but the vomiting continued, and during each of the following three days the infant lost 30 grams, so that its weight on November 29 th was 3,490 grams. We both saw that an operation was imperative, and on the morning of November $30 \mathrm{th}$ the child was removed to St. Elizabeth's Hospital. Its general condition was still fairly good. The temperature, taken daily during the last days at home, was normal. Stethoscopic examination showed no thoracic disease. The abdomen was soft to the touch, without distension or swelling; now and then faint peristaltic movements were noticeable on the left side. The umbilical wound was well healed; it had been "dressed since the shrivelling of the cord with cotton-wool moistened with 1 per cent. silver nitrate solution.

Operation.

Directly after admission the stomach was washed out and the skin having been disinfected with soap, water, and spirit, abdominal section was undertaken under ether The incision was made a little to the left of the middle line, and was between 7 and $8 \mathrm{~cm}$. long. After the anterior sheath of the rectus had been laid bare, Mosetig batiste was sewn to the edges of the skin with continuous silk suture so that the integuments were completely covered. On opening the peritoneum the dilated stomach protruded into the wound, and was traced along the dilated pylorus into the duodenum, which was uniformly of about two fingerbreadths in width, as far as it could be traced to the upper side of the transverse mesocolon. But below the colon, where the intestine reappeared, at the flexura duodeno-jejunalis, it was seen to have collapsed to the calibre of an ordinary pencil, about 8 millimetres in diameter. The remaining part of the small intestine was examined quickly, especially its lower portion, but no stenosis was discovered.

On that account I made a duodeno-entero-anterior anastomosis-that is to say, a coil of small intestine about four inches below the flexura duodeno-jejunalis was drawn up in front of the transverse colon, and united to tho duodenum about the junction of the pars superior and pars descendens: Anastomosis to the lower part of the pars descendens was impracticable.

The intestines were held during the operation by Doyen's straight soft intestinal forceps; first, continuous seroserous suture was applied, then a continuous suture through all the layers the whole way round; and, finally, a continuous sero-serous suture on the front (all sutures of Turner's silk No. 1). When a stomach tube was passec through it a good deal of air and greenish fluid was dits. charged. The intestinal forceps was removed, and immediately afterwards the jejunum began to fill. The walls of the abdominal incision were united with decp catgut sutures, and interrupted silk sutures were applied to the sheath of the rectus and skin. 'The dressing was fixed with mastisol. The child was little affected either by the anaesthetic ar by the operation, which lasted about 14 hours. It took $35 \mathrm{c.cm}$. of ether.

A few hours after the operation I began to give the infant a weak mixture of milk and water, about 30 c.cm. every two hours; it vomited a little several times in the course of the day, and at 8 p.m. more violently, so that the stomach tube was used, and a little greenish fluid evacuated: At 7.p.m. an enema was given, but withont any result.

On December list the rectal temperature was $37.7^{\circ}$ and $37.4^{\circ} \mathrm{C}$. There was again much vomiting. On December 2nd the temperature was $37.4^{\circ}$ and $37.1^{\circ} \mathrm{C}$. Since the previous day the infant had hat eleven meals of $30 \mathrm{c.cm}$. each. He had vomited three times during the day, and on December 1st was given one teaspoinful of castor oil twice and three enemata, and had altogether four alvine discharges, which without any doubt contained digested milk. The child's appear the was slight sickness for some days; the boriels acted daily, and the stools soon appeared quite normal. The temperature" also fell to normal. Five days after the operation the child was sent home to be suckled by his mother, who could not be admitted to the hospital. The dressin is remained untouched till the fourteenth day, when all sutures were removed; the wound had healed by first intention.

The infant's weight decreased during the first five days 90 grams more, and was now 3,400 grams, or 900 grains less than at its birth; but afterwards it increased continuously, and considerably more than 250 grams a week for several months. We soon allowed meals every third hour, and when a few weeks had passed the child could sleep the whole night without food. He is now remarkably quiet for his age and is vigorous and well developed; his weight in the middle of October, 1915, was 11,200 grains.

\section{Commentary.}

As I mentioned in the first part of this report, medical literature relates but one instance of the recovery of an infant operated on for congenital atresia of the small intestines. ${ }^{1}$ The child was a boy, born at term November 6th, 1910; he was taken to a free consultation; it was stated that he had never had any movement of the bowels and that he had romited constantly ever since his birth 
The abdomen was rather swollen and flatulent. On November 14th laparotomy was performed, and complete atresia of the small intestine detected. At a point normally between the middle and lower third of the small intestine the bowel was completely missing, being repre sented by a cord along the edge of the mesentery connecting the blind ends. After applying Doyen's intestinal forceps, entero-entero-anastomosis was performed with two rows of silk suture. After the operation the temperature rose to $105.8^{\circ} \mathrm{F}$., but soon fell and became normal, and five months later the child had quite recovered.

Congenital atresia of the small intestines is, on the whole, very uncommon. In the foundling hospital at Petrograd Theremin reported nine cases among 150,000 children, and I myself have come across only two cases among 41,000 children in the Royal Lying-in Hospital at Copenhagen.

Different hypotheses have been advanced to explain the pathogeny of atresia of the smull intestine, but the most probable is that advanced by Tandler, ${ }^{2}$ the Viennese anatomist. On examining eleven human fetuses aged from 30 to 60 days he found that on the thirtieth day an epithelial proliferation begins in the duodenum, and results in a more or less complete obstruction of its lumen. This obstruction is greatest on about the forty. fifth day, and seems to have ceased on about the sixtieth day. According to Tandler's theory, congenital atresia of the small intestine is due to persistent physiological epithelial obstruction. ${ }^{3}$ This theory was afterwards confirmed by E. Irenter, and especially by $\mathrm{Hj}$. Forssner " of Stockholm; the latter writer maintains that a narrow epithelial stenosis may become a complete atresia later on in fetal life, and in this way he explains the presence of meconium below the atresia, as noted above in the report of my own case.

I think all will agree that the treatment of atresia of the small intestine must be surgical, but as to the kind of operation opinion still differs greatly. From the perusal of cases recorded (even during the later decennia), it will be noticed that in an astonishing majority only enterostomy has been performed, and it has relways resulted in sudden death, associated with an enormous rise of temperature; yet even in $1902 \mathrm{H}$. Braun ${ }^{s}$ recommended this procedure as the normal method for deep-seated atresia of the small intestine. Naturally, I cannot share Braun's view; on the contrary, I maintain that if we are dealing with a fairly strong infant, without any other signs of bad deformity, we ought to perform a laparotomy, making the abdominal incision large enough to enable us to see where the obstruction is seated, and also to make sure that no second stenosis be present. Then the operator should make the anastomosis which the particular case demands. It will very seldom be possible to postpone the operation as long as in my case. As yet I havo not been able to discover any account of anastomosis being performed for atresia of the duodenum. It will be noticed in the history of the recorded cases that while almost all the infants that have undergone this operation developed an exceedingly ligh temperature, although only enterostomy was undertaken, the infant operated on more radically by Fockens also got very high fever, yet completely recovered.

As we caunot suppose that failure is due in every case to defective personal asepsis on the part of the surgeon, we must direct our attention to the special source of the infection in the child itself. There is a risk on two sides -namely, from the skin and from the contents of the intestines. As is well known, the integuments of an infant during the first weeks of its life are always infected from the umbilical wound, and the delicate skin cannot stand any strong disinfectants. In order to eliminate this danger, $I$ in the first place dressed the umbilical wound with cotton-wool moistened in a 1 per cent. solution of silver nitrate, before the putrefaction of the cord; and what was of still more importance, I sewed Mosetig batiste to the margins of the wound before-laying open the sheath of the rectus; so that the intestines and compresses could not touch the skin. It cannot be doubted that the stagnant and decomposed contents of the stomach involve a great dungor of peritonitis ; it is necessary, therefore, if there be any suspicion of atresia, that the greatest care and cleanliness be taken in the feeding of the infant, hence only an experienced nurse should be entrusted with a case of this kind. The strictest care should be taken to prevent any of the contents of the intestines getting into the peritoneum during the operation. I chose the antecolic type of anastomosis as being the easiest to perform. The fact was that I was not able to apply it to the lower part of the duodenum on account of the adhesion of that part of the bowol to the posterior abdominal wall. A retrocolic anastomosis might for purely theoretical reasons have seemed to allow of almost normal anatomical conditions, but I consider that the drawing of the gut through the mesocolon and the more difficult application of anastomosis would have increased the risk of the operation considerab!y. Later, on reading Fockens's report, I was greatly interested in the fact that ho had argued in a similar way.

\section{REFERENCFs.}

1 P. Fockens, Nederland. Tijhschr. $f$, Geneesk., 1911, vol. i, No. 18: and Zentralbl. f. Chir., 19il, p. 532. 2 Morphologiaches Jah rbuch, 1902,

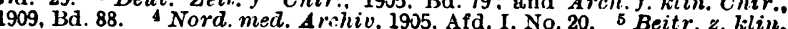
Chir., 1902, Bd. 34, p. 993.

\section{SOME HINTS ON TIME SATING IN OPERATIONS.}

BY EDWARD HARRISON, M.A., M.D., F.R.C.S., HONORARY SURGEON, HULL TOYAL INFIRMARY.

That an operation performed rapidly, without, of course, in any way impairing its efficient performance, is desirable in the interest of the patient, is, I think, admitted by all Indeed, in many cases-for instance, a case of ruptured ectopic pregnancy-rapidity in operating may easily make the difference of life or death to the patient; and as neces. sarily the surgeon has frequently to undertake such cases, it is imperative that he should be able to act promptly, quickly, and safely. 'This is, however, not the point $I$ an about to discuss; I am taking it for granted that it is better for the patient that any operation should bo expeditiously performed. The gain, too, is not confined to the patient, but is time saved to the busy surgeon, and in hospital work, where operation succeeds operation, a saving of time is a great gain to all concerued.

How is time to be saved? First and foremost, I most emphatically state that it lies in efficient co-operation between the surgeon, house-surgeon, and theatre sister. I am, of course, now speaking of hospital work; any work in private must necessarily fall short of this. By con stantly working together the surgeon, house-surgeon, and sister play into each other's hands and assist one another as do partners in any game-bridge or football, for instance.

Of the trio, perhaps the sister plays the most important rôle; a sister, such as we havo at present at the Hull Royal Infirmary, must save hours in the course of a month's operating. A good sister knows the peculiarities of each surgeon she has to work with, and is ever ready to hand him the instrument he needs, never keeps him waiting a moment while she threads a needle but is ever alert, so that I often wonder that after five or six hours' work it is possible to remain good tempered and willing for anything further.

Then, too, much time is saved in a hospital between operations by efficient drilling of the nurses. I often sit and admire the way in which preparations are made for the next operation. After the dressings are applied the porters are summoned, the house-surgeon wheels the table out of the theatre, and then changes his glores. The sister changes hers, and prepares the instruments for the coming case; one nurse swabs down the floor with a squeegee, another takes the bowls away, and replaces them with freshly sterilized ones; no one is in a hurry, all works as smoothly as a silent running motor car, and the theatre is ready before the anaesthetist has the next patient under.

After this, then, given a capable house-surgeon and a reliable theatre sister, what can the surgeon himself do in the saiving of time? This, of course, varies with the individual; a man who in his youth has been accustomed to use his fingers as individual digits, who has practised such arts as carpentry, inechanical drawing, or piano playing, has all his fingers under control, and can use each one as required without any effort. The boy who is fond of using his fingers in any deft way, such as familiarity with the difrerent knots in use among sailors, one who delights 